\title{
IMPACT OF PHYLLOPLANE MANAGEMENT ON MICROBIAL POPULATIONS
}

\author{
N.W. WAIPARA, F.O. OBANOR and M. WALTER
}

\author{
HortResearch, Canterbury Research Centre, P.O. Box 51, Lincoln \\ Corresponding author: nwaipara@hortresearch.co.nz
}

\begin{abstract}
The impact of apple orchard management on leaf microbial populations was investigated during the 2001/2002 growing season. Apple leaves were collected in spring and autumn from two certified organic (Bio-Gro) and IFP (Integrated Fruit Production) managed apple orchards, at each of three New Zealand sites (Hawke's Bay, Nelson and Canterbury). Phylloplane epiphytes were recovered by leaf washing using a stomacher blender, and the micro-organisms enumerated using serial plate dilutions. The micro-organisms were separated into recognisable taxonomic units (RTUs) based on colony morphology. Analysis of both spring and autumn samples showed that leaves from all three sites from organic orchards harboured significantly more colony forming units than were found on leaves from IFP orchards. Overall population richness (based on RTUs/ leaf sample) was also significantly higher in organic than IFP orchards. Keywords: organic, IFP, richness, CFU, apple leaves.
\end{abstract}

\section{INTRODUCTION}

The effects of chemicals and other production practices on particular groups of microorganisms have been used to evaluate environmental impacts on agricultural ecosystems (Edwards et al. 1996). Microbial population groups that are sensitive to such biotic and anthropogenic disturbances are termed bioindicators. Microbial activity, species abundance and distribution patterns of bioindicators change under different land management and production systems, and these changes can be measured to determine the relative impacts of practices, such as pesticide use, on the surrounding environment (van Bruggen \& Semenov 2000). A higher level of microbial biodiversity can generally be regarded as being an indicator of a healthy robust ecosystem (Hawksworth 1995), and methods have been developed to assess diversity of microbial populations for monitoring environmental disturbances (O'Donnell et al. 1995).

Unique and diverse microbial phylloplane (leaf surface) populations have been described in apple orchards in New Zealand (Pennycook \& Newhook 1981), and some components of these epiphytic populations were shown to be sensitive to seasonal variations. This study aims to compare microbial populations under organic and IFP apple orchard systems and to determine impact and sensitivity of different production practices on population abundance and richness across three climatic regions during spring and autumn.

\section{MATERIALS AND METHODS}

During the 2001/02 growing season, the population abundance and richness of apple phylloplane micro-organisms were determined in Canterbury, Hawke's Bay and Nelson Braeburn orchards. At each site, two Bio-Gro orchards and two orchards that followed IFP guidelines were selected. In spring, the leaves were sampled from Hawke's Bay, Nelson and Canterbury orchards on 3/12/01,5/12/01 and 10/12/01 respectively. Twelve trees were selected at random from the centre of each orchard and ten of the older leaves on each tree were picked at random from branches at an average height of $1.7 \mathrm{~m}$. Micro-organisms were washed off the leaves by adding $40 \mathrm{ml}$ sterile phosphate buffer $(100 \mathrm{mM}$ potassium

New Zealand Plant Protection 55:125-128 (2002) 
phosphate $+0.05 \%$ Tween 80 ) into plastic bags containing the leaf samples and using a stomacher blender for $1 \mathrm{~min}$. Aliquots of $100 \mu \mathrm{l}$ of $10^{-2}$ and $10^{-3}$ serial dilutions of the suspension were spread onto duplicate potato dextrose agar (PDA, Merck) plates. Isolation plates were incubated at $20 \pm 1^{\circ} \mathrm{C}$ and a $12 \mathrm{~h}$ photoperiod for 7 days. Following incubation, microbial colony forming units (CFUs) were enumerated and classified into four main groups: bacteria, smooth yeasts, hyphal yeasts and filamentous fungi. The organisms in each group were further classified into Recognisable Taxonomic Units (RTUs) based on different colony growth patterns and phenotypic morphologies (Bakker et al. 2002). The population abundance (CFUs/leaf) and the species richness (RTUs/leaf) were determined after 7 days. In autumn, the orchards and trees used in spring were re-visited. The leaves were sampled as described above from Hawke's Bay, Nelson and Canterbury orchards on the 4/3/02, 5/3/02 and 11/3/02 respectively. All autumn samples were processed in the same manner as the spring samples, except that serial dilutions of $10^{-3}$ and $10^{-4}$ were plated. Statistical analyses were undertaken using ANOVA to compare the variances of all data sets.

\section{Population abundance}

\section{RESULTS}

Similar patterns of microbial abundance were observed at all three sites, whereby there were significantly more $(\mathrm{P}<0.05)$ phylloplane CFUs enumerated from trees in organic orchards (mean $=29.4 \mathrm{CFU} / \mathrm{leaf}$ ) than from trees in IFP orchards (mean $=16.3$ CFU/leaf) (Fig. 1). A significant seasonal effect was also obtained as all sites had higher $(\mathrm{P}<0.05) \mathrm{CFU}$ counts in autumn (mean $=38.3 \mathrm{CFU} / \mathrm{leaf})$ than spring (mean $=7.4 \mathrm{CFU} /$ leaf) (Fig. 1). Although CFU counts did differ between sites, for example Canterbury IFP orchards had higher CFU counts in autumn than Nelson or Hawke's Bay, the overall differences between sites were not significant $(\mathrm{P}>0.05)$.

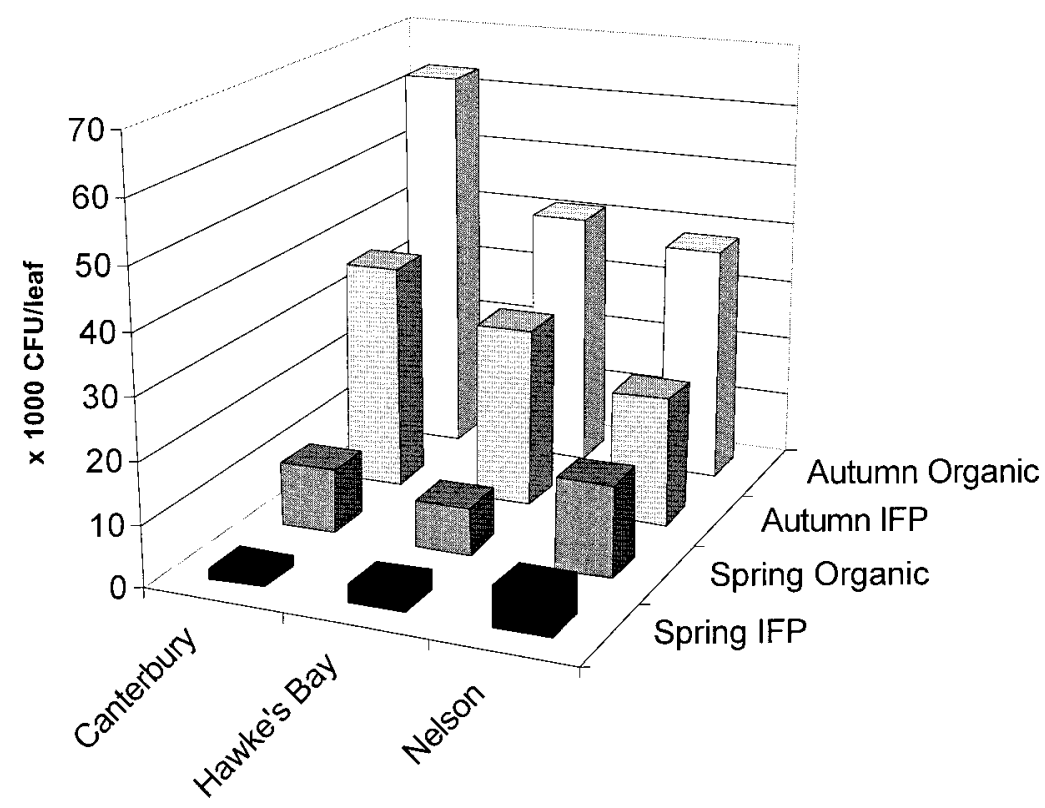

FIGURE 1: Abundance of apple phylloplane micro-organisms isolated from organic and IFP orchards in spring and autumn at three locations. 


\section{Population richness}

There was an overall significant difference $(\mathrm{P}<0.05)$ between production systems, as organic orchards had higher mean richness values (9.2 RTUs/leaf) than IFP orchards (7.3 RTUs/leaf) (Fig. 2). Similar trends were observed at all sites in both autumn and spring, except for Hawke's Bay in autumn when no significant difference was observed between organic and IFP orchards. No significant differences between RTU values were observed between the three sites. A total of 91 different RTUs were distinguished: 5 bacteria, 35 yeasts, 11 hyphal yeasts and 40 filamentous fungi. Hyphal yeasts have been determined as species of Aureobasidium, Trichosporon and Geotrichum. Further taxonomic differentiation and identification of the remaining population groups is currently underway.

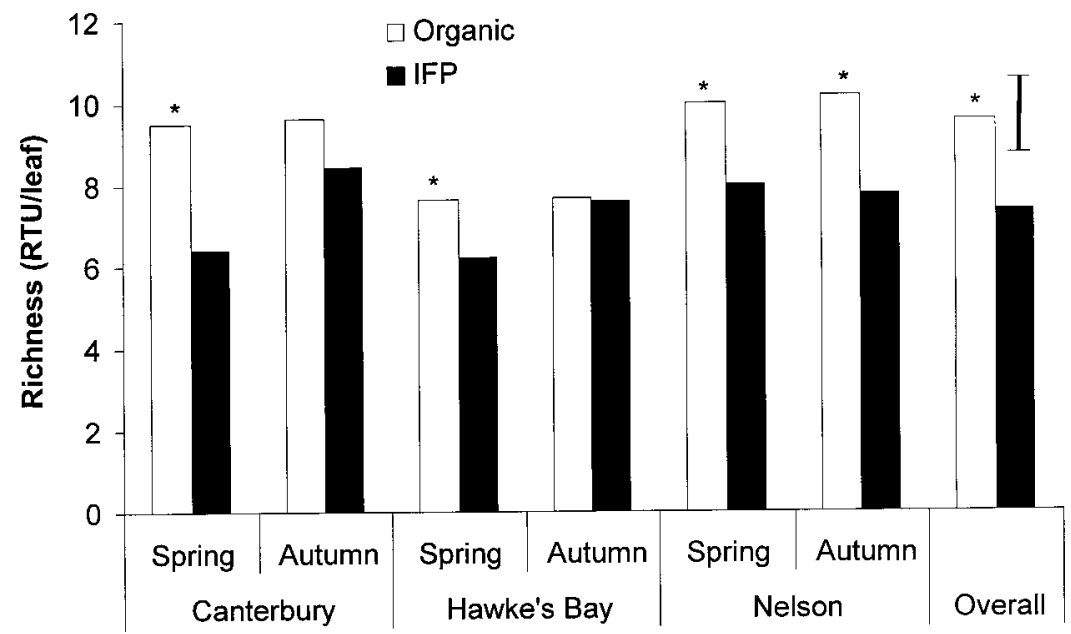

FIGURE 2: Population richness of apple phylloplane micro-organisms isolated from organic and IFP orchards during spring and autumn at three locations. A significant difference $(P<0.05)$ between organic and IFP systems within a season and locations is indicated by *. The overall standard error bar for all data is shown.

\section{DISCUSSION}

An overall higher abundance and diversity of micro-organisms was observed in organic orchards across all sites during spring and autumn, compared with that observed for IFP orchards. A comparable result was also reported for micro-organism populations over spring in Canterbury orchards in a linked study (Bakker et al. 2002), which further validates both methodology and some of the observations reported here. Despite lower population richness in IFP orchards, both studies do show some recovery of richness in Canterbury and Hawke's Bay orchards by autumn. Microbial apple phylloplane populations are therefore not only sensitive to seasonal variation (Pennycook \& Newhook 1981) but also sensitive to different orchard management practices.

As similar population dynamics were observed at all three sites, some components of the phylloplane microflora may be less sensitive to regional and climatic variations. We therefore conclude that epiphytic phylloplane micro-organisms have the potential to act as bioindicators of different production practices in New Zealand apple orchards. However, further taxonomic investigation will be required to identify the exact 
components of the microflora that are the most sensitive and useful bioindicators. Development of rapid diagnostic methodologies, such as DNA probes, will be required before such micro-organisms can be validated as indicators of different orchard management practices.

Organic agricultural production systems and produce have previously been reported to exhibit increased microbial activity, abundance and diversity compared with conventional systems (Waipara \& Torp 2001, 2000). Whilst New Zealand's apple IFP system aims to reduce and more efficiently use agrochemicals in orchards, beneficial micro-organism populations may still be adversely affected. The use of agrochemicals has been shown to reduce microbial populations on the apple phylloplane (Hislop \& Cox 1969), including species that are antagonistic to the apple blackspot pathogen Venturia inaequalis (Simard et al. 1957). Therefore, further studies are required to elucidate such impacts in New Zealand orchards. This research will then have the potential to improve current IFP and organic programmes through improved disease management. Avoiding unnecessary loss of naturally occurring beneficial organisms is one of the simplest means of taking advantage of them.

\section{ACKNOWLEDGEMENTS}

We would like to acknowledge Dr Ian Horner, Mary Horner and Dr Peter Shaw for arranging collection of Hawke's Bay and Nelson samples, Dr Chris Frampton and Dr Peter Alspach for statistical analyses, and Kirsty Boyd-Wilson and Sally Allan for technical assistance. This work was funded by the Foundation for Research, Science and Technology.

\section{REFERENCES}

Bakker, G.R.; Frampton, C.M.; Jaspers, M.V.; Stewart, A.; Walter, M. 2002: Assessment of phylloplane microorganism populations in Canterbury apple orchards. N.Z. Plant Prot. 55:129-134.

Edwards, C.A.; Subler S.; Chen, S.K.; Bogomolov, D.M.; Straalen, N.M.; Krivolutsky, D.A. 1996: Essential criteria for selecting bioindicator species, processes, or systems to assess the environmental impact of chemicals on soil ecosystems. In: Straalen, N.M. ed. Bioindicator systems for soil pollution. Kluwer Academic Publishers, Dordrecht. Pp. 67-84.

Hawksworth, D.L ed. 1995: Biodiversity, measurement and estimation. Chapman \& Hall, London. 140 p.

Hislop, E.C.; Cox, T.W. 1969: Effects of captan on the non-parasitic microflora of apple leaves. Trans. Brit. Mycol. Soc. 52: 233-235.

O'Donnell, A.G.; Goodfellow, M.; Hawksworth, D.L. 1995: Theoretical and practical aspects of the quantification of biodiversity among microorganisms. In: Hawksworth, D.L ed. Biodiversity, measurement and estimation. Chapman \& Hall, London. Pp. 65-73.

Pennycook, S.R.; Newhook F.I. 1981: Seasonal changes in the apple phylloplane microflora. N.Z. J. Bot. 19: 273-283.

Simard, J.; Pelletier, R.L.; Coulson, J.G. 1957: Screening of microorganisms inhabiting apple leaves for their antibiotic properties against Venturia inaequalis (Cooke) Wint. Rep. Queb. Soc. Prot. Plant 39: 59-67.

van Bruggen, A.H.C.; Semenov, A.M. 2000: In search of biological indicators for soil health and disease suppression. Appl. Soil Ecol. 15: 13-24.

Waipara, N.W.; Torp, M. 2000: Biodiversity of microfungi in soils, plant roots and foods: A comparison between organic and conventional agricultural ecosystems. N.Z. Plant Prot. 53: 454.

Waipara, N.W.; Torp, M. 2001: A comparison of Botrytis fruit rot and microfungal populations on conventionally and organically produced strawberries. N.Z. Plant Prot. 54: 258. 